\title{
.
}

\section{Online and telephone access to general practice: a cross-sectional patient survey}

\section{Carol Bryce ${ }^{1 *}$, Matthew DL O'Connell ${ }^{2}$, Jeremy Dale ${ }^{1}$, Martin Underwood ${ }^{3}$, Helen Atherton ${ }^{1}$}

${ }^{1}$ Unit of Academic Primary Care, Warwick Medical School, University of Warwick, Coventry, UK; ${ }^{2}$ Department of Population Health and Environmental Sciences, King's College London, London, UK; ${ }^{3}$ Warwick Clinical Trials Unit, Warwick Medical School, University of Warwick, Coventry, UK

\begin{abstract}
Background: Improving access to primary health care in the UK has focused on the use of telephone and online access, but little is known about how awareness of and use varies between different patient groups.
\end{abstract}

Aim: To determine how patients are interacting with telephone and online channels for accessing general practice services and information, and to analyse how this varies according to patient characteristics and health status.

Design \& setting: A cross-sectional self-administered survey of adult patients in general practices across the West Midlands, UK.

Method: Descriptive statistics were used to show participants' awareness of and interaction with online information sources and remote access. Multivariable logistic regression was used to model the relationships between demographic and health characteristics, and awareness and use of online services and alternatives to face-to-face consultations (for example, telephone).

Results: A total of 2789 patients (19.0\% response rate) from 43 general practices participated. The study found $60.8 \%$ ( $n=1651 / 2715)$ of participants were aware of online services and $30.3 \%(n=$ 811/2674) reported having used one. Daily internet usage and frequently visiting the GP showed the strongest associations with knowledge and use of online services.

Conclusion: The study shows that there is the potential for inequitable awareness and use of telephone and online services in general practice populations. Given that their use has greatly increased owing

*For correspondence: c.bryce. $1 @$ warwick.ac.uk

Competing interest: See page 8

Received: 26 November 2020

Accepted: 19 January 2021

Published: 09 June 2021

(C)This article is Open Access: CC BY license (https://creativecommons.org/licenses/by/4.0/)

Author Keywords: digital health, primary health care, inequalities, internet, telephone

Copyright (C) 2021, The Authors; DOI:10.3399/BJGPO.2020.0179 to the COVID-19 pandemic, future service design will need to ensure equity is taken into account.

\section{How this fits in}

Evidence on how patients interact with telephone and online channels for accessing general practice services and information is lacking. The study shows that before the COVID-19 pandemic, awareness and use of telephone and online channels of access in the UK was higher in certain groups within the population. Less frequent internet use and not attending the general practice were associated with lower awareness and use of online services. When accounting for this, the study also shows differences according to factors including age, education level, and deprivation. The onset of the pandemic led to the rapid introducation of telephone and video consultation, and there remains an urgent need for strategies to avoid exacerbating existing inequalities when moving forward. 


\section{Introduction}

Communications technology is seen as a tool for improving access to primary health care. ${ }^{1-3}$ In the UK there has been a recent policy drive for increased use of digital services. ${ }^{3,4}$ However, before the COVID-19 pandemic, adoption by general practices was slow. ${ }^{5,6}$ At the onset of the pandemic the UK NHS rapidly implemented telephone triage and remote consultation (telephone, online, and video) in response, as a way to reduce the number of face-to-face consultations. ${ }^{7}$ GP face-to-face consultations dropped during March 2020 from 80.5\% to 51.0\%. ${ }^{8}$ As health services plan for the future, it is important to consider benefits ${ }^{9}$ and consequences that may be associated with rapid implementation of remote access.

From 2019 it was mandatory for GPs in England to provide patients with online appointment bookings, online repeat prescriptions, and access to their medical records online. ${ }^{10}$ Data from early 2020 show fewer than one-third of patients (29.6\%) in England were registered to use any of these online services ${ }^{11}$ and uptake was low (ordering prescription online [18.8\%], booking appointment online [18.1\%], and requesting access to patient records online [5.8\%]). ${ }^{12}$ In the UK most individuals are connected to the internet, ${ }^{12}$ but frequency of use and ability to use it varies greatly. Some groups may be disadvantaged by a move to online access; for example, older adults, those with a disability or long-term health condition, low socioeconomic groups, migrants, and ethnic minorities. ${ }^{13}$

Online and telephone access to general practice services was examined by conducting a crosssectional survey of patients registered at general practices in the West Midlands. How patients were interacting with telephone and online channels for accessing general practice services and information was determined, and how this varied according to patient characteristics and health status was analysed. The survey now also provides baseline data before the COVID-19 pandemic.

\section{Method}

\section{Study design}

A cross-sectional, self-administered survey was conducted with adults registered at general practices across the West Midlands. The survey was administered between February and June 2019.

\section{Survey instrument}

The survey had 32 questions. It was designed to collect data on demographic and health factors known to influence whether and how patients access online services and/or general practice, as well as on awareness and use of online services. ${ }^{14-17}$ Validated questions were used from the NHS General Practice Patient Survey ${ }^{18}$ (on internet usage, caring responsibilities, the responder's experience of using their GP surgery, its website and getting an appointment, and repeat prescription) and the Office for National Statistics ${ }^{19}$ (on participant characteristics including age, sex, ethnic group, education level, and health status).

Questions relating to access, including knowledge and use of alternatives to a face-to-face consultation and private online providers (outside of the NHS), were devised by the study team, drawing on surveys conducted in this field and other related work. ${ }^{20,21}$

The survey was piloted by conducting five cognitive interviews with members of the public to check understanding, particularly in relation to the questions devised by the study team. ${ }^{22}$

\section{Sampling and recruitment}

The survey was aimed to sample approximately 15000 people. Based on estimates from previous surveys conducted in general practice, a $20 \%$ response rate was expected to be seen. ${ }^{23,24}$ Patients were sampled at the general practice level. It was aimed to recruit 40 practices selected to ensure the inclusion of a wide range of patients, sampling general practices purposively to ensure variation in rural and urban locations, list size, deprivation score, and proportion of patients from minority ethnic groups. Sampling of patients was proportional to general practice list size, achieved by randomly sampling $5 \%$ of eligible patients registered at each practice. Patients were excluded if they were aged $<18$ years, at the end of life, or lacked capacity to consent to participate in the survey. An index of multiple deprivation score was assigned to participants within each practice based on the area score 
for location of that practice. ${ }^{25}$ This scores practices from one to ten with a score of one indicating the most deprivation. ${ }^{25}$

\section{Data collection}

Patients were sent a paper copy of the survey with a postage-paid return envelope. Participants were given the option to complete the survey online using a web link or a quick response (QR) code on the front of the paper survey. The online survey was administered using the software package Qualtrics. A reminder letter was sent to all sampled patients 2 weeks after the initial survey. This letter thanked them for participating (where they had) and prompted a response where they had not.

\section{Data analysis}

Descriptive statistics were used to show participants' awareness of and interaction with online information sources and remote access. Ethnic group was split into two categories: White; and Black, Asian, Mixed, and Other (BAMO). It was not possible to split the categories further owing to small numbers of responders from BAMO groups. Multivariable logistic regression models were used to model the relationships between demographic characteristics (age, sex, ethnic group, education level, and employment status), health characteristics (number of long-term conditions and number of visits to GP in past year), other personal characteristics (level of internet use and caring responsibilities), and awareness and use of services. The predictor variables were selected a priori based on the factors known to influence whether and how patients access online services and/or general practice that comprised the questions in the survey. Univariable models for each variable were also constructed for comparative purposes (see Supplementary Tables S1-S4). These models included clustered standard errors to account for the survey design (individuals nested within practices). Participating general practices were contacted to determine what online and telephone services they offered. General practices not offering any particular online or telephone service featured on the survey were excluded from analysis for that service. Results are expressed as odds ratios (OR) and $95 \%$ confidence intervals (95\% Cls). The statistical software package Stata (version 15) was used.

Table 1 Practice characteristics

\begin{tabular}{|c|c|}
\hline Location & Practices, $N=43, n$ \\
\hline Urban & 32 \\
\hline Rural & 11 \\
\hline \multicolumn{2}{|c|}{ List size (number of patients) } \\
\hline Small <6000 & 16 \\
\hline Medium 6000-12000 & 20 \\
\hline Large $>12000$ & 7 \\
\hline \multicolumn{2}{|c|}{ Deprivation (IMD 2019) ${ }^{a}$} \\
\hline $1-3$ & 14 \\
\hline $4-7$ & 17 \\
\hline $8-10$ & 12 \\
\hline
\end{tabular}

Ethnic group, BAMO, \% ${ }^{b, c}$

\begin{tabular}{lc}
\hline$<5$ & 16 \\
\hline $5-10$ & 7 \\
\hline $11-20$ & 5 \\
\hline $21-50$ & 10 \\
\hline 50 & 5
\end{tabular}

${ }^{a} 1=$ most deprived. ${ }^{b}$ West Midlands BAMO population: $17.4 \% .{ }^{29}$ cHighest: $82.1 \%$; lowest: $1.0 \%$. BAMO = Black, Asian, Mixed, and Other. IMD = Index of Multiple Deprivation. 
Table 2 Characteristics of responders

\begin{tabular}{|c|c|c|c|}
\hline & & $n$ & $\%$ \\
\hline \multirow{5}{*}{$\begin{array}{l}\text { Age, years, } \\
n=2756\end{array}$} & $18-34$ & 248 & 9.0 \\
\hline & $35-54$ & 680 & 24.7 \\
\hline & $55-64$ & 589 & 21.4 \\
\hline & $65-74$ & 723 & 26.2 \\
\hline & $\geq 75$ & 516 & 18.7 \\
\hline \multirow{3}{*}{$\begin{array}{l}\text { Sex, } \\
n=2757\end{array}$} & Male & 1181 & 42.8 \\
\hline & Female & 1567 & 56.8 \\
\hline & Prefer not to say & 9 & 0.3 \\
\hline \multirow{2}{*}{$\begin{array}{l}\text { Ethnic group, } \\
n=2728\end{array}$} & White & 2496 & 91.5 \\
\hline & BAMO & 232 & 8.5 \\
\hline \multirow{6}{*}{$\begin{array}{l}\text { Education, } \\
n=2657\end{array}$} & No formal qualifications & 419 & 15.8 \\
\hline & Secondary level & 386 & 14.5 \\
\hline & Further & 588 & 22.1 \\
\hline & Higher & 1115 & 42.0 \\
\hline & Still studying & 18 & 0.7 \\
\hline & Other & 131 & 4.9 \\
\hline \multirow[b]{2}{*}{$\begin{array}{l}\text { Parent or guardian for any } \\
\text { young person aged }<16 \text { years } \\
\text { living at home, } \\
n=2706\end{array}$} & Yes & 402 & 14.9 \\
\hline & No & 2304 & 85.1 \\
\hline \multirow{3}{*}{$\begin{array}{l}\text { Caring responsibilities for } \\
\text { family or friends, } \\
n=2695\end{array}$} & No & 2112 & 78.4 \\
\hline & Yes ( $\leq 9$ hours/week) & 334 & 12.4 \\
\hline & Yes ( $\geq 10$ hours/week) & 249 & 9.2 \\
\hline \multirow{2}{*}{$\begin{array}{l}\text { Health status: long-term } \\
\text { physical or mental health } \\
\text { conditions, disabilities, or } \\
\text { illnesses, } \\
n=2647\end{array}$} & Yes & 1360 & 51.4 \\
\hline & No & 1287 & 48.6 \\
\hline \multirow{3}{*}{$\begin{array}{l}\text { Frequency of using general } \\
\text { practice services in past } 12 \\
\text { months, } \\
n=2748\end{array}$} & 0 & 255 & 9.3 \\
\hline & $1-5$ & 1652 & 60.1 \\
\hline & $>5$ & 841 & 30.6 \\
\hline \multirow{3}{*}{$\begin{array}{l}\text { Internet use in the past } 3 \\
\text { months, } \\
n=2646\end{array}$} & Daily & 1788 & 67.6 \\
\hline & Less than daily & 420 & 15.9 \\
\hline & Never & 438 & 16.6 \\
\hline
\end{tabular}

$\mathrm{BAMO}=$ Black, Asian, Mixed, and Other.

\section{Results}

In total, 43 general practices (7\% of those in the West Midlands) participated; see Table 1. Of 14 694 patients sampled across the practices, 2789 (19.0\%) responded, with 2413 (86.5\%) returning the survey via post and 376 (13.5\%) completing it online. All participating practices had a website, and offered online booking of appointments and of repeat prescriptions. Telephone appointments or callback systems were available in 40 practices, including six practices that operated a telephone triage system after all of the day appointments were booked. No practices offered email or video consultation. 
Table 3 Awareness and use of online services

\begin{tabular}{lcccc}
\hline & Awareness, $\mathbf{n = 2 7 1 5}$ & Use, $\boldsymbol{n}=\mathbf{2 6 7 4}$ \\
\hline Any online service & $\boldsymbol{n}$ & $\%$ & $\mathbf{n}$ & $\%$ \\
\hline Booking appointments & 1651 & 60.8 & 811 & 30.3 \\
\hline Ordering repeat prescriptions & 1479 & 54.5 & 552 & 20.6 \\
\hline Accessing medical records & 1362 & 50.2 & 584 & 21.8 \\
\hline & 629 & 23.2 & $172^{\mathrm{a}}$ & 7.8 \\
\hline Private online general practice services & Awareness, $\mathbf{n}=\mathbf{2 6 2 8}$ & Use, $\mathbf{n}=\mathbf{2 6 9 7}$ \\
\hline Private online GP consultations & 657 & 25.0 & 126 & 4.7 \\
\hline
\end{tabular}

${ }^{\mathrm{a}} N=2207$

Responders' characteristics are in Table 2. Around half of responders $(51.4 \% ; n=1360 / 2647)$ reported they had a long-term physical or mental health condition, disability, or illness. Of these, $26.6 \%(n=680 / 2556)$ reported a physical health problem, $7.9 \%(n=201 / 2556)$ a sensory condition, $13.4 \%(n=343 / 2556)$ a mobility problem, and $5.6 \%(n=143 / 2556)$ a mental health problem. The majority of participants $(89.0 \% ; n=2447 / 2748)$ reported their experience of general practice and of making appointments as good (71.7\%; $n=1963 / 2744)$. Most had visited their practice at least once in the past 12 months $(60.1 \% ; n=1652 / 2748)$. Patient awareness of their general practice website was high $(85.0 \% ; n=2266 / 2666)$ with $42.1 \%(n=1147 / 2725)$ having accessed the website on at least one occasion. Awareness of alternatives to face-to-face consultations as a concept was low with $0.5 \%$ ( $n=$ $12 / 2643)$ aware of email consultation and $0.5 \%(n=14 / 2643)$ of video consultation.

\section{Awareness and use of online services}

Table 3 outlines the percentage of patients aware of and using different online services.

In the multivariable model, an association between awareness of online booking for appointments and daily internet usage was observed $(\mathrm{OR}=4.39,95 \% \mathrm{Cl}=2.98$ to 6.46 ), higher frequency of GP visits $(O R=2.13,95 \% \mathrm{Cl}=1.41$ to 3.24$)$, having higher education qualifications $(\mathrm{OR}=1.83,95 \% \mathrm{Cl}$ $=1.35$ to 2.48 ), having at least one long-term condition ( $O R=1.35,95 \% \mathrm{Cl}=1.10$ to 1.66 ), being retired ( $O R=1.51,95 \% \mathrm{Cl}=1.09$ to 2.08 ), and being female (OR $=1.5,95 \% \mathrm{Cl}=1.24$ to 1.80 ) (see Supplementary Table S5). Usage patterns showed the same associations with daily internet usage (OR $=14.92,95 \% \mathrm{Cl}=6.84$ to 32.57$)$, higher frequency of $\mathrm{GP}$ visits (OR $=10.64,95 \% \mathrm{Cl}=5.01$ to 22.59$)$, having further education qualifications $(O R=1.90,95 \% \mathrm{Cl}=1.33$ to 2.73$)$, having at least one longterm condition $(\mathrm{OR}=1.47,95 \% \mathrm{Cl}=1.20$ to 1.81$)$, and being female $(\mathrm{OR}=1.43,95 \% \mathrm{Cl}=1.14$ to 1.79). There was also a weak association between practice deprivation score and awareness of online appointment booking with higher deprivation associated with lower awareness $(\mathrm{OR}=1.09,95 \% \mathrm{Cl}=$ 1.02 to 1.15$)$, this was less clear for use (OR $=1.05,95 \% \mathrm{Cl}=0.99$ to 1.12$)$.

An association between awareness of online repeat prescriptions being offered and daily internet use was observed $(\mathrm{OR}=5.14,95 \% \mathrm{Cl}=3.74$ to 7.07$)$, visiting the $\mathrm{GP}>5$ times in the past 12 months $(\mathrm{OR}=2.22,95 \% \mathrm{Cl}=1.56$ to 3.14$)$, having a long-term condition $(\mathrm{OR}=1.81,95 \% \mathrm{Cl}=1.50$ to 2.18$)$, being retired $(\mathrm{OR}=1.54,95 \% \mathrm{Cl}=1.17$ to 2.03$)$, having education qualifications $(\mathrm{OR}=1.53,95 \% \mathrm{Cl}$ $=1.15$ to 2.03$)$, being female $(\mathrm{OR}=1.34,95 \% \mathrm{Cl}=1.12$ to 1.61$)$, aged $55-64$ years $(\mathrm{OR}=1.47,95 \%$ $\mathrm{Cl}=1.03$ to 2.10 ), and lower deprivation $(\mathrm{OR}=1.10,95 \% \mathrm{Cl}=1.03$ to 1.17 ) (see Supplementary Table S6). Reported use of the repeat prescription service online showed the association was strongest for those who visited the $\mathrm{GP} \geq 5$ times in the past 12 months $(\mathrm{OR}=2.22,95 \% \mathrm{Cl}=1.56$ to 3.14$)$ and those who used the internet daily ( $O R=11.86,95 \% \mathrm{Cl}=6.57$ to 21.42$)$. It was also significant for those with education qualifications that were not further or higher education $(\mathrm{OR}=1.79,95 \% \mathrm{Cl}=1.10$ to 2.90$)$, having an informal caring role of $\geq 10$ hours per week ( $O R=1.51,95 \% \mathrm{Cl}=1.08$ to 2.11 ), being retired $(\mathrm{OR}=1.55,95 \% \mathrm{Cl}=1.11$ to 2.16$)$, and lower deprivation $(\mathrm{OR}=1.11,95 \% \mathrm{Cl}=1.02$ to 1.21$)$.

Awareness of online access to medical records was associated with using the internet every day $(\mathrm{OR}=4.20,95 \% \mathrm{Cl}=2.90$ to 6.09$)$, visiting the $\mathrm{GP}>5$ times in the past 12 months $(\mathrm{OR}=3.29,95 \% \mathrm{Cl}$ $=1.80$ to 6.03$)$, being older (aged $65-74$ years) $(\mathrm{OR}=1.77,95 \% \mathrm{Cl}=1.24$ to 2.52$)$, having a long-term 
condition $(\mathrm{OR}=1.38,95 \% \mathrm{Cl}=1.12$ to 1.70$)$, being retired $(\mathrm{OR}=1.40,95 \% \mathrm{Cl}=1.06$ to 1.85$)$, and lower deprivation $(\mathrm{OR}=1.18,95 \% \mathrm{Cl}=1.07$ to 1.30$)$. Being from a non-White ethnic group was also associated with awareness ( $O R=2.05,95 \% \mathrm{Cl}=1.35$ to 3.11 ) (see Supplementary Table S7). Access was more strongly associated with use of the internet ( $O R=8.00,95 \% \mathrm{Cl}=2.63$ to 24.30 ), frequently visiting the $\mathrm{GP}(\mathrm{OR}=19.88,95 \% \mathrm{Cl}=2.50$ to 157.87$)$, and having a long-term condition $(\mathrm{OR}=2.21$, $95 \% \mathrm{Cl}=1.34$ to 3.63 ).

\section{Awareness and use of telephone consultation}

Telephone consultations were widely offered as an alternative to face-to-face consultations. Overall, $55.7 \%$ of responders $(n=1471 / 2643)$ were aware of telephone consultation and $36.7 \%(n=987 / 2691)$ had used the service. Awareness of telephone consultation was associated with being female $(\mathrm{OR}=$ $1.82,95 \% \mathrm{Cl}=1.48$ to 2.23$)$, frequent internet use $(\mathrm{OR}=1.81,95 \% \mathrm{Cl}=1.27$ to 2.59$)$, visiting the $\mathrm{GP}$ $>5$ times in the past 12 months ( $\mathrm{OR}=2.74,95 \% \mathrm{Cl}=1.76$ to 4.24$)$, having a long-term condition (OR $=1.40,95 \% \mathrm{Cl}=1.12$ to 1.75$)$, being a parent of a child aged $<16$ years $(\mathrm{OR}=1.44,95 \% \mathrm{Cl}=1.08$ to 1.93 ), and having an informal caring role of $\geq 10$ hours per week (OR $=1.54,95 \% \mathrm{Cl}=1.08$ to 2.20 ) (see Supplementary Table S8). Reported use of telephone consultations followed the same pattern, with higher education $(\mathrm{OR}=1.51,95 \% \mathrm{Cl}=1.04$ to 2.20$)$ also being associated with use of telephone consultation.

\section{Discussion}

\section{Summary}

The study shows that before the pandemic, in the study population, awareness and use of online primary care services was higher in individuals who used the internet daily, and those who attended general practice frequently. Having a long-term condition, being female, and registered at a practice in an area of low deprivation were all associated with greater awareness and use of telephone and online services. Also, the study has demonstrated awareness and use of telephone and online access being associated with being retired and with higher education levels. Parents and carers were most likely to use telephone access. It was observed that awareness of the practice website and online services was higher than usage.

\section{Strengths and limitations}

The survey included a diverse range of practices. A $19.0 \%$ patient response rate is consistent with unsolicited community postal surveys. ${ }^{26}$ However, it is likely that those who responded were more interested in the topic and may have differed in other ways to the non-responders; therefore, their responses cannot necessarily be extrapolated to the entire community.

Responders were older than the resident population in the West Midlands (aged $\geq 65$ years, survey: 45.1\%; West Midlands: $18.6 \%{ }^{27}$ ). However, apart from high consultation rates in infants, consultation rates increased with increasing age from the lowest levels in the 15-24 age group. ${ }^{6}$ Consultation rates are also higher in areas of high deprivation, ${ }^{28}$ and, in this study, deprivation score was only available at the practice level that lacked granularity. This means the authors cannot be confident that they engaged a wide enough range of patients across the deprivation gradient and that in controlling for deprivation in the models they used only an approximation for deprivation level. The views of ethnic minority groups are also under-represented in the findings, with the proportion of responders from these groups lower than in the general population (White ethnic group, this survey: 91.5\%; West Midlands region: $82.7 \%{ }^{29}$ ). The findings of this study should be interpreted in light of these limitations.

The survey tool used validated questions from both the Office for National Statistics and the NHS General Practice Patient Survey, alongside questions developed to address the topic of access to general practice. Although additional validation of the survey as a whole was not conducted, cognitive interviews were used with public contributors to check understanding of the survey instrument before it was used in the study population.

Practices were sampled purposively and consequently practice level variables were not included, other than deprivation (as a proxy for patient deprivation level), in the models. Clustered standard errors were included to account for the nesting of participants within practices. Practice level factors, 
such as location (rural versus urban), often influence patient behaviour in general practice and so any future surveys should consider these practice level variables.

\section{Comparison with existing literature}

The data found similar results to the national General Practice Patient Survey by NHS England, ${ }^{11}$ with $89.0 \%$ of the responders and $83 \%$ of the national survey rating overall experience of their general practice as good, and $71.7 \%$ of the present study's sample compared with $67 \%$ of the national sample rating their experience of making an appointment as good. This suggests the participants are broadly similar in views, despite the sample in the present study being smaller and skewed towards older people.

It was found that online services, including online booking, repeat prescription ordering, and access to patient records, were available at the majority of the general practices at the time of the survey, but uptake was limited. This is in line with national data that shows in January 2020 less than one-third of patients in England (29.6\%) were registered for at least one online service. ${ }^{30,31}$ By 31 December 2020 , the number had risen to $32.4 \%,{ }^{30}$ a modest increase given that the majority of contacts with UK general practices became remote during the COVID-19 pandemic. ${ }^{32}$ Previous research shows that uptake of online or digital services remain low owing to a lack of awareness or engagement within practice populations alongside staff reservations and understanding about appropriate use. ${ }^{33,34}$ It is also known that deprivation has an impact on service quality, satisfaction, and usage. ${ }^{35,36}$

\section{Implications for research and practice}

The COVID-19 pandemic markedly increased levels of use of telephone consultation and online consultation, and it looks likely that the rapid move to using online methods of contact and access will be retained after the pandemic to a certain degree. ${ }^{7,9}$ The sample was comprised of mostly older participants from a White ethnic group, who were retired. It is likely that awareness and use of online and telephone services is even lower in groups known to be disadvantaged in relation to accessing services; for example, people who use the internet less frequently, those who visit the general practice infrequently, older people, those with lower levels of education, and those who live in areas of high deprivation. Practices should raise awareness of services available, being cautious to avoid assumptions over how patients get their information. Awareness of the general practice website was high, but less than half of the sample had used it, so this is unlikely to provide a primary information source for patients about what services are available, nor does information provision alone lead to use. Patients may require support to both learn about and use services that provide alternative routes of access.

Patients who regularly attend the practice differ in relation to awareness and use of online services relative to those who attend less frequently if at all, and so different approaches are likely to be needed depending on the patient.

The burden of COVID-19 ill health and economic disadvantage is not equally distributed across communities, ${ }^{37-39}$ and may be hitting hardest where awareness and use of online and telephone access is lowest, risking inequality. Future research studies should explore the role of the practice, as well as patient characteristics, in determining awareness and use of services. They should also aim to produce practical recommendations about what can be done in everyday practice to ensure patients have a suitable route of access available to them.

\section{Funding}

This study was supported by Martin Underwood's National Institute for Health Research (NIHR) Senior Investigator Award, and by a NIHR Clinical Research Network West Midlands Chief Investigator grant.

Ethical approval

Ethical approval was granted by North East — York Research Ethics Committee (reference number: 18/NE/0333).

Provenance

Freely submitted; externally peer reviewed. 


\section{Competing interests}

$\mathrm{MU}$ is chief investigator or co-investigator on multiple previous and current research grants from the UK National Institute for Health Research, Arthritis Research UK and is a co-investigator on grants funded by the Australian NHMRC. He is an NIHR Senior Investigator. He has received travel expenses for speaking at conferences from the professional organisations hosting the conferences. He is a director and shareholder of Clinvivo Ltd that provides electronic data collection for health services research. He is part of an academic partnership with Serco Ltd, funded by the European Social Fund, related to return to work initiatives. He is a co-investigator on two NIHR funded studies receiving additional support from Stryker Ltd. He has accepted honoraria for teaching/lecturing from consortium for advanced research training in Africa. Until March 2020 he was an editor of the NIHR journal series, and a member of the NIHR Journal Editors Group, for which he received a fee.

\section{References}

1. Danish Medical Association. [Activity and economy in general practice]. [Article in Danish]. 2017; https://www. laeger.dk/nyhed/aktivitet-og-oekonomi-i-almen-praksis (accessed 14 May 2021).

2. Pearl R. Kaiser Permanente Northern California: current experiences with internet, mobile, and video technologies. Health Aff 2014; 33(2): 251-257. DOI: https://doi.org/10.1377/hlthaff.2013.1005

3. Royal College of General Practitioners. The 2022 GP: a vision for general practice in the future NHS. 2013; https:// www.rcgp.org.uk/ /media/Files/Policy/A-Z\%20policy/The-2022-GP-A-Vision-for-General-Practice-in-the-FutureNHS.ashx (accessed 14 May 2021).

4. NHS England. Investment and evolution: a five-year framework for GP contract reform to implement the NHS Long Term Plan. 2019; https://www.england.nhs.uk/wp-content/uploads/2019/01/gp-contract-2019.pdf (accessed 14 May 2021).

5. News Team DHI. Netscape navigators.Digital Health 2013; 21 Feb; https://www.digitalhealth.net/2013/02/ netscape-navigators (accessed 14 May 2021).

6. Hobbs FDR, Bankhead C, Mukhtar T, et al. Clinical workload in UK primary care: a retrospective analysis of 100 million consultations in England, 2007-14. Lancet 2016; 387(10035): 2323-2330. DOI: https://doi.org/10.1016/ S0140-6736(16)00620-6

7. Thornton J. Covid-19: how coronavirus will change the face of general practice forever. BMJ 2020; 368: $\mathrm{m} 1279$. DOI: https://doi.org/10.1136/bmj.m1279

8. NHS Digital. Appointments in general practice - March 2020. 2020; https://digital.nhs.uk/data-and-information/ publications/statistical/appointments-in-general-practice/march-2020 (accessed 14 May 2021).

9. Duckett S. What should primary care look like after the COVID-19 pandemic? Aust J Prim Health 2020; 26(3): 207-211. DOI: https://doi.org/10.1071/PY20095

10. NHS Digital. Appointments in general practice January 2020. 2020; https://digital.nhs.uk/data-and-information/ publications/statistical/appointments-in-general-practice/january-2020 (accessed 14 May 2021).

11. NHS England, Ipsos MORI. GP Patient Survey national report 2020 publication. 2020; https://www.gp-patient.co. uk/downloads/2020/GPPS_2020_National_report_PUBLIC.pdf (accessed 21 May 2021).

12. Office for National Statistics. Internet users, UK: 2019. 2019; https://www.ons.gov.uk/businessindustryandtrade/itan dinternetindustry/bulletins/internetusers/2019 (accessed 14 May 2021).

13. Public Health England. Local action on health inequalities: improving health literacy to reduce health inequalities. 2015; https://assets.publishing.service.gov.uk/government/uploads/system/uploads/attachment_data/file/460709/ 4a_Health_Literacy-Full.pdf (accessed 14 May 2021).

14. Ford JA, Turley R, Porter T, et al. Access to primary care for socio-economically disadvantaged older people in rural areas: a qualitative study. PLoS One 2018; 13(3): e0193952. DOI: https://doi.org/10.1371/journal.pone.0193952

15. Burt J, Lloyd C, Campbell J, et al. Variations in GP-patient communication by ethnicity, age, and gender: evidence from a national primary care patient survey. Br J Gen Pract 2016; 66(642): e47-e52. DOI: https://doi.org/10.3399/ bjgp15X687637

16. Huntley AL, Johnson R, Purdy $\mathrm{S}$, et al. Measures of multimorbidity and morbidity burden for use in primary care and community settings: a systematic review and guide. Ann Fam Med 2012; 10(2): 134-141. DOI: https://doi.org/ 10.1370/afm.1363

17. Stormacq C, Van den Broucke S, Wosinski J. Does health literacy mediate the relationship between socioeconomic status and health disparities? Integrative review. Health Promot Int 2019; 34(5): e1-e17. DOI: https://doi.org/10. 1093/heapro/day062

18. Ipsos MORI. GP Patient Survey: surveys and reports. 2017; https://www.gp-patient.co.uk/surveysandreports2017 (accessed 21 May 2021).

19. UK Data Service. Opinions and lifestyle survey, internet access module, January, February and April, 2017. 2017; https://beta.ukdataservice.ac.uk/datacatalogue/studies/study?id=8299\&type=Data\%20catalogue (accessed 14 May 2021).

20. Brant $\mathrm{H}$, Atherton $\mathrm{H}$, Ziebland $\mathrm{S}$, et al. Using alternatives to face-to-face consultations: a survey of prevalence and attitudes in general practice. Br J Gen Pract 2016; 66(648): e460-e466. DOI: https://doi.org/10.3399/ bjgp16X685597 
21. van Velthoven $\mathrm{MH}$, Atherton $\mathrm{H}$, Powell $\mathrm{J}$. A cross sectional survey of the UK public to understand use of online ratings and reviews of health services. Patient Educ Couns 2018; 101(9): 1690-1696. DOI: https://doi.org/10.1016/ j.pec.2018.04.001

22. Drennan J. Cognitive interviewing: verbal data in the design and pretesting of questionnaires. J Adv Nurs 2003; 42(1): 57-63. DOI: https://doi.org/10.1046/j.1365-2648.2003.02579.x

23. Peeters JM, Krijgsman JW, Brabers AE, et al. Use and uptake of eHealth in general practice: a cross-sectional survey and focus group study among health care users and general practitioners. JMIR Med Inform 2016 ; 4(2): e11. DOI: https://doi.org/10.2196/medinform.4515

24. Newbould J, Abel G, Ball S, et al. Evaluation of telephone first approach to demand management in English general practice: observational study. BMJ 2017; 358: j4197. DOI: https://doi.org/10.1136/bmj.j4197

25. Ministry of Housing, Communities \& Local Government. The English Indices of Deprivation 2019 (loD2019). $2019 ;$ https://assets.publishing.service.gov.uk/government/uploads/system/uploads/attachment_data/file/835115/ loD2019_Statistical_Release.pdf (accessed 14 May 2021).

26. Sinclair M, O'Toole J, Malawaraarachchi M, Leder K. Comparison of response rates and cost-effectiveness for a community-based survey: postal, internet and telephone modes with generic or personalised recruitment approaches. BMC Med Res Methodol 2012; 12(1): 132. DOI: https://doi.org/10.1186/1471-2288-12-132

27. Office for National Statistics. Population estimates for the UK, England and Wales, Scotland and Northern Ireland: mid-2019. 2020; https://www.ons.gov.uk/peoplepopulationandcommunity/populationandmigration/ populationestimates/bulletins/annualmidyearpopulationestimates/mid2019estimates (accessed 14 May 2021).

28. Mukhtar TK, Bankhead C, Stevens S, et al. Factors associated with consultation rates in general practice in England, 2013-2014: a cross-sectional study. Br J Gen Pract 2018; 68(670): e370-e377. DOI: https://doi.org/10. 3399/bjgp18X695981

29. Office for National Statistics. Regional ethnic diversity. 2020; https://www.ethnicity-facts-figures.service.gov.uk/ukpopulation-by-ethnicity/national-and-regional-populations/regional-ethnic-diversity/latest (accessed $21 \mathrm{May} 2021$ ).

30. NHS Digital. Patient Online Management Information (POMI). 2018; https://digital.nhs.uk/data-and-information/ data-tools-and-services/data-services/general-practice-data-hub/patient-online-management-information-pomi (accessed 14 May 2021).

31. Edwards HB, Marques E, Hollingworth W, et al. Use of a primary care online consultation system, by whom, when and why: evaluation of a pilot observational study in 36 general practices in South West England. BMJ Open 2017; 7(11): e016901. DOI: https://doi.org/10.1136/bmjopen-2017-016901

32. Murphy M, Scott LJ, Salisbury C, et al. Implementation of remote consulting in UK primary care following the COVID-19 pandemic: a mixed-methods longitudinal study. Br J Gen Pract 2021; 71(704): e166-e177. DOI: https:// doi.org/10.3399/BJGP.2020.0948

33. Atherton $\mathrm{H}$, Brant $\mathrm{H}$, Ziebland $\mathrm{S}$, et al. Alternatives to the face-to-face consultation in general practice: focused ethnographic case study. Br J Gen Pract 2018; 68(669): e293-e300. DOI: https://doi.org/10.3399/bjgp18X694853

34. Rodgers M, Raine G, Thomas S, et al. Informing NHS policy in 'digital-first primary care': a rapid evidence synthesis. Health Serv Deliv Res 2019; 7(41): 1-124. DOI: https://doi.org/10.3310/hsdr07410

35. Fisher R, Dunn P, Asaria M, Thorlby R. Briefing: Level or not? Comparing general practice in areas of high and low socioeconomic deprivation in England. London: The Health Foundation; 2020.

36. Fisher R, Fraser C. Who gets in? What does the 2020 GP patient survey tell us about access to general practice? https://www.health.org.uk/news-and-comment/charts-and-infographics/who-gets-in (accessed 14 May 2021).

37. Bambra C, Riordan R, Ford J, Matthews F. The COVID-19 pandemic and health inequalities. J Epidemiol Community Health 2020; 74(11): 964-968. DOI: https://doi.org/10.1136/jech-2020-214401

38. Douglas M, Katikireddi SV, Taulbut M, et al. Mitigating the wider health effects of covid-19 pandemic response. BMJ 2020; 369: m1557. DOI: https://doi.org/10.1136/bmj.m1557

39. Khilnani A, Schulz J, Robinson L. The COVID-19 pandemic: new concerns and connections between eHealth and digital inequalities. JICES 2020; 18(3): 393-403. DOI: https://doi.org/10.1108/JICES-04-2020-0052 